\title{
Perception of preconception care among women attending antenatal care clinic in a tertiary health care hospital in south east, Nigeria
}

Henry I Nwaolisa ${ }^{1}$, Onyeka Chukwudalu Ekwebene ${ }^{1,}{ }^{*}$, Darlington C Obi ${ }^{2}$, Obiageli F Emelumadu ${ }^{2}$, Akagha K.T Jerry ${ }^{1}$ and Timothy Ugochukwu Igwe ${ }^{1}$

${ }^{1}$ Faculty of Medicine, Nnamdi Azikiwe University, Awka, Nnewi Campus, Nigeria.

2 Department of Community Medicine, Nnamdi Azikiwe University, Nnewi, Nigeria.

Magna Scientia Advanced Research and Reviews, 2021, 02(02), 013-027

Publication history: Received on 24 March 2021; revised on 29 April 2021; accepted on 02 May 2021

Article DOI: https://doi.org/10.30574/msarr.2021.2.2.0036

\begin{abstract}
Preconception care is the provision of biomedical, behavioral and social health interventions to women and couples before conception occurs. This study aimed to assess women's knowledge, practice, perceived views and ideas and associated factors in preconception care amongst women attending antenatal care at Nnamdi Azikiwe University Teaching Hospital, Nnewi, Anambra state, Nigeria. A facility based cross-sectional study conducted among 150 randomly selected reproductive age group women who attended antenatal clinic from September 9 to September 26, 2020.The data were collected using self-administered and interviewer-administered questionnaires. The data were analyzed using Statistical Package for Social Sciences version 20.0. The study revealed 31.3\% overall knowledge of preconception care. The knowledge level on preconception care was significantly associated with occupation, level of education, residence, number of pregnancies and past obstetrics complications. Age has no association with the level of knowledge. Only about one-fifth of the participants have good knowledge of the importance of folic acid use prior to and during pregnancy $(17.3 \%), 32 \%$ had wrong knowledge and the rest had no knowledge $(50.7 \%)$. Majority of the participants $(87.7 \%)$ had prospective views concerning preconception care encouraging every woman to partake in it. In this finding, the level of women's knowledge on preconception care was very low. Having a high level of education, living in urban area and having an obstetrics history were associated with good knowledge. The finding also showed positive views on the uptake and practice preconception care. This finding suggests that there is a need to give more emphasis on educating women on preconception care with the sole aim of achieving a sound maternal and child health.
\end{abstract}

Keywords: Preconception Care; Interventions; Conception; Maternal; Mortality.

\section{Introduction}

Preconception care is the provision of biomedical, behavioral and social health interventions to women and couples before conception occurs. It aims at improving their health status, and reducing behaviors and individual and environmental factors that contribute to poor maternal and child health outcomes. ${ }^{1,2}$ It is a component of comprehensive obstetrics care, can be described as a specialized form of care for women of reproductive age before the onset of pregnancy to detect, treat, or counsel them about the preexisting medical and social conditions that may militate against safe motherhood and delivery of a healthy offspring. Its ultimate aim is to improve maternal and child health, in both the short and long term. ${ }^{1,2}$

According to the World Bank estimates, Nigeria's Maternal Mortality Rate, MMR is still as high as 821 per 100,000 live births. ${ }^{4}$ Worst still, of the 303,000 women that died globally due to complications of pregnancy and child births in 2015 ,

${ }^{*}$ Corresponding author: Onyeka Chukwudalu Ekwebene

Faculty of Medicine, Nnamdi Azikiwe University, Awka, Nnewi Campus, Nigeria. 
58,000 women died in Nigeria. ${ }^{4}$ At the just- concluded maternal health meeting held in Brussels, Belgium, experts noted that while global maternal mortality dropped by about 43 percent since 1990, Nigeria still ranked highest among subSaharan African nations with high maternal deaths. ${ }^{4}$ Co- Chair of the Bill and Melinda Gates Foundation, Mr. Bill Gates, had said Nigeria is one of the most dangerous places in the world to give birth and 4th country with the worst maternal mortality rate ahead of Sierra Leone, Central African Republic and Chad. This calls for drastic improvement in reproductive health. ${ }^{4}$

Preconception care to women and couples before and between pregnancies improves the chances of mothers and babies being healthy. Preconception care is a prerequisite in reducing maternal mortality rate which is paramount for health workers to promote the awareness and practice at every contact with women of reproductive age.

In 2012, the World Health Organization reviewed its policy on preconception care to improve maternal and child health. Despite the policy, there is still a lot to be done in promoting and utilization of preconception care in Nigeria.

This study will document the perception of preconception care among women attending antenatal care services at Nnamdi Azikiwe University Teaching Hospital, Nnewi. The study will serve as a representation of women of reproductive age group in Nigeria. The study findings may be used by the appropriate authorities to formulate policies that will enhance the awareness and utilization of preconception care in Nigeria thus improving perinatal outcome.

The objective of this study was to determine the knowledge and beliefs of preconception care among pregnant women attending antenatal clinic and how does this affect their seeking behavior, to determine the perceived factors (facilitators and hindrances) associated with intentions and decision-makings regarding preconception care, to ascertain the demographic influence on preconception uptake among women attending antenatal care clinic and to determine the perceived views and ideas of preconception care among the participants at Nnamdi Azikiwe University Teaching Hospital Nnewi Anambra state.

\subsection{Research questions}

- What knowledge on preconception care do pregnant women attending antenatal clinic at Nnamdi Azikiwe University Teaching Hospital Nnewi Anambra state have?

- What is the uptake level of preconception care among pregnant women attending antenatal clinic and how does this affect their seeking behavior at Nnamdi Azikiwe University Teaching Hospital Nnewi,Anambra state?

- What factors influence the knowledge and uptake of preconception care among pregnant women attending antenatal clinic and how does this affect their seeking behavior at Nnamdi Azikiwe University Teaching Hospital Nnewi, Anambra state?

- What are the women's perceived views, beliefs and ideas concerning preconception care?

\section{Methodology}

\subsection{Study Location}

The study is a cross-sectional survey design conducted at Nnamdi Azikiwe University Teaching Hospital(NAUTH), Nnewi located in Anambra State, South east Nigeria.. Nnewi is a cosmopolitan city whose population is estimated to be at 391,277 according to the 2006 Nigeria Population Census and is the $2^{\text {nd }}$ largest city in Anambra with estimated area of approximately 107 square kilometer. The city is bounded by Umuoji on the north, Awka-etiti on the east, Umuoji on the west and by Ukpor on the west ${ }^{22}$. Majority of the people in Nnewi are traders of large, medium and small scale calibers, second only to farming. The Nkwo Nnewi market is the $2^{\text {nd }}$ largest market in Anambra,well known for its automobile trade 22 .

The monarchical system of Nnewi is headed by an Igwe, presently Igwe K.O.N Orizu, who will be succeeded by his son after his death. They have two traditional festivals which are usually celebrated; Afiaolu and Ofala Igwe ${ }^{22}$.

NAUTH is a tertiary health institution which provides a wide range of medical ,surgical, diagnostic, outpatient, rehabilitative and support services with diverse specialties NAUTH has several annexes at different locations which include Neni, Ukpo, Oba, Umunya and Awka all within Anambra state it has about 19 wards and 294 bed capacity and 
can boast of more than 2700 staffs $^{23}$.The Obstetrics and Gynecology department has 6 units and it runs an everyday antenatal and gynecology clinic to provide adequate maternal health services ${ }^{23}$

\subsection{Study Design}

A hospital-based descriptive cross-sectional study design was used to access the perception of preconception care among women attending antenatal clinic because the findings from cross-sectional studies are representative and can be generalized and there search and data on perception of preconception services was collected .This study design allowed for the description and reporting of things the way they were. It also allowed for the description of the characteristics of the study participants and their behavior per training the perception of preconception care services.

\subsection{Sample size determination}

The representative sample size was obtained using fisher's formula ${ }^{18}$

$$
n=\frac{Z^{2} p q}{d^{2}}
$$

Where;

$\mathrm{n}=$ the desired sample size

$\mathrm{z}=$ the standard normal deviate at $95 \%$ confidence level

$\mathrm{p}=$ the prevalence

$q=1-p$

$\mathrm{d}=$ the degree of precision

$\mathrm{P}=0.89$ is the prevalence of the target population quoted from previous literature ${ }^{18}$

$q=(1-P)=0.11$ and $d$ is precision limit of 0.05

$\mathrm{n}=(1.96)^{2}(0.89)(0.11) /(0.005)^{2}$

Attrition: is $10 \%$ of the sample size with which the sample size would be adjusted to take care of improperly filled or misplaced questionnaires.

$10 / 100 * 150=15$

Minimum sample size $=150+15=165$

The sample size was calculated to be 150 , and using an attrition rate of $10 \%, 15$ respondents were included making a calculated sample size of 165 .

\subsection{Sampling Technique}

Simple random sampling method was used. Every reproductive age woman attending antenatal clinic who met the inclusion criteria was entirely chosen by chance. The daily antenatal register was used in making the random samples. The individual numbers of the subjects in the daily register of women booked for each day was written on a piece of paper and put in a nylon bag thereafter selected randomly. Women who came for their first booking visit were also randomly selected. About 25 women come for antenatal visits on most days of the week and the clinic runs for the 5 working days in a week.

\subsection{Study population}

The study population is the women attending antenatal clinic at Nnamdi Azikiwe University Teaching Hospital, Nnewi, Anambra state. 


\subsection{Inclusion Criteria}

The study subjects included women of reproductive age (15- 49 years)who were present at the antenatal clinic and consented to participate in the study.

\subsection{Exclusion Criteria}

The study excluded women of reproductive age who were not able to give consent and relevant data.

\subsection{Study instruments}

The study utilized a self-administered semi-structured questionnaires and mostly interviewer-based questionnaires as the primary method of data collection.

\subsection{Data Collection}

Four assistants were involved in the data collections on different days having been fully trained on the study and mode of research data collection. The interviewer-based was used due to the distress most of the pregnant women encounter and also due to the prompt consultation at the clinic preventing some of the women from fully attempting the questionnaire.The self-administered methods was also used because of their open nature to allow a deeper understandingofthebeliefs,practice,opinions, andviewsconcerningtheperception of preconception care. Only about 10 data were collected on each clinic day having been selected randomly from the about 25 women attending the clinic on the five working days of the week necessitating the data collection spanning for about three weeks. At the end of each collection, the women were briefed on the on what preconception care is all about including its components. Majority of the women consented to the research and gave warm responses to further instructions on answering the questionnaires, only few refused to partake in the study.

\subsection{Data Analysis}

I analyzed the data using the Statistical Package for Social Sciences IBM version 20.0.Chi-square was used to determine the level of significance at $p<0.05$.The analyzed data were represented in the form of tables and charts.

\subsection{Ethical Consideration}

All participants were informed about the scope and purpose of the study and also informed that it is voluntary to participate, without compensation, and that their medical care would not be compromised if they refused to participate in the survey. Informed consent was obtained in every case prior to being given the questionnaire, their confidentiality and anonymity was assured as no name was required in the questionnaire, no incentive was provided to patients who participated and only a few refused to participate. Having written a proposal and submitted the study received full ethical approval letter from the Ethics committee, Nnamdi Azikiwe University Teaching Hospital, Nnewi.

\section{Results}

More than half of the participants were aged 25-34(61.3\%),the rest were 35-44(26\%), 15-24(11.3\%) and the least age distribution were 45 and above(1.3\%).Nearly all the participants were Christians(98\%) and only $2 \%$ being muslim.98.7\% were married. On the residence of participants, more than three-quarter resided in the urban area (76.7\%).39.3\% of participants were self-employed, with $36.0 \%$ employed,9.3\% student and $15.4 \%$ unemployed. On educational level, about half of the participants had attained secondary level, $44.7 \%$ tertiary level, $7.3 \%$ with primary level and only $2.7 \%$ having no formal education.

Below half of the participants(45.3\% )has had about 3-4 pregnancies and $43.3 \%$ are having pregnancy at the time of study or are in their second pregnancy, only $11.3 \%$ has had about five or more pregnancies. On the past obstetrics complications, more than half of the participants(61.5\%) never had any complication in their previous pregnancies, $23.1 \%$ has had a miscarriage, $8.5 \%$ stillbirth,3.4\% prolonged labor and 3.4\% preeclampsia. 
Table 1Socio-demographic characteristics of participants

\begin{tabular}{|l|l|l|l|}
\hline Variable & Category & Frequency & Percentage (\%) \\
\hline Age distribution & $15-24$ & 17 & 11.3 \\
\cline { 2 - 4 } & $25-34$ & 92 & 61.3 \\
\cline { 2 - 4 } & $35-44$ & 39 & 26.0 \\
\cline { 2 - 4 } & 45 and above & 2 & 1.3 \\
\cline { 2 - 4 } & Total & 150 & 100 \\
\hline Marital status & Single & 2 & 1.3 \\
\cline { 2 - 4 } & Married & 148 & 98.7 \\
\cline { 2 - 4 } & Total & 150 & 100 \\
\hline \multirow{5}{*}{ Occupation } & Student & 14 & 9.3 \\
\cline { 2 - 4 } & Employed & 54 & 36.0 \\
\cline { 2 - 4 } & Self employed & 59 & 39.3 \\
\cline { 2 - 4 } & Unemployed & 23 & 15.4 \\
\cline { 2 - 4 } & Total & 150 & 100 \\
\hline Religion & Christian & 147 & 98 \\
\cline { 2 - 4 } & Islam & 3 & 2 \\
\cline { 2 - 4 } & Total & 150 & 100 \\
\hline \multirow{5}{*}{ Level of education } & No formal education & 4 & 2.7 \\
\cline { 2 - 4 } & Primary & 11 & 7.3 \\
\cline { 2 - 4 } & Secondary & 68 & 45.3 \\
\cline { 2 - 4 } & Tertiary & 67 & 44.7 \\
\cline { 2 - 4 } & Total & 150 & 100 \\
\hline \multirow{5}{*}{ Residence } & Rural & 35 & 23.3 \\
\cline { 2 - 4 } & Urban & 115 & 76.7 \\
\cline { 2 - 4 } & Total & 100 \\
\hline \multirow{5}{*}{} & & & 29 \\
\hline
\end{tabular}

Table 2 Obstetrics History

\begin{tabular}{|l|c|c|}
\hline Variable & Frequency & Percentage \\
\hline Number of Pregnancies & & \\
\hline $1-2$ & 65 & 43.3 \\
\hline $3-4$ & 68 & 45.3 \\
\hline 5 and above & 17 & 11.3 \\
\hline Past Obstetrics complications & & \\
\hline None & 72 & 61.5 \\
\hline Miscarriage & 27 & 23.1 \\
\hline Stillbirth & 10 & 8.5 \\
\hline Prolonged labour & 4 & 3.4 \\
\hline Preeclampsia & 4 & 3.4 \\
\hline
\end{tabular}


Table 3 Knowledge of Preconception Care

\begin{tabular}{|l|c|c|}
\hline Knowledge level & Frequency & Percentage (\%) \\
\hline Adequate knowledge & 47 & 31.3 \\
\hline Inadequate knowledge & 103 & 68.7 \\
\hline TOTAL & 150 & 100 \\
\hline
\end{tabular}

Table 4 Source of Information on Preconception Care

\begin{tabular}{|l|c|c|}
\hline Place & Frequency & Percentage (\%) \\
\hline Hospital & 40 & 67.8 \\
\hline Church & 4 & 6.8 \\
\hline In Community & 2 & 3.4 \\
\hline Radio/Television & 1 & 1.7 \\
\hline Internet & 11 & 18.6 \\
\hline School & 1 & 1.7 \\
\hline
\end{tabular}

Table 5 Knowledge level of Preconception Care against Socio-demographic Variables

\begin{tabular}{|l|l|l|l|}
\hline Variable & Adequate & Inadequate & \\
\hline Age & $5(29.4 \%)$ & $12(70.6 \%)$ & \\
\hline $15-24$ & $28(30.4 \%)$ & $64(69.6 \%)$ & $x^{2}=0.460, \mathrm{df}=1, \mathrm{P}>0.05$ \\
\hline $25-34$ & $13(33.3 \%)$ & $26(66.7 \%)$ & \\
\hline $35-44$ & $1(50 \%)$ & $1(50 \%)$ & \\
\hline 45 and above & & & \\
\hline Occupation & $7(50 \%)$ & $7(50 \%)$ & \\
\hline Student & $27(50 \%)$ & $27(50 \%)$ & $\chi^{2}=20.345, \mathrm{df}=4, \mathrm{P}<0.05$ \\
\hline Employed & $10(16.9 \%)$ & $49(83.1 \%)$ & \\
\hline Self-employed & $3(13.6 \%)$ & $19(86.4 \%)$ & \\
\hline Unemployed & \multicolumn{5}{|l}{} \\
\hline Level of education & $1(25 \%)$ & $3(75 \%)$ & \\
\hline No formal & $2(20 \%)$ & $8(80 \%)$ & $x^{2}=21.601, \mathrm{df}=4, \mathrm{P}<0.05$ \\
\hline Primary & $10(14.7 \%)$ & $58(85.3 \%)$ & \\
\hline Secondary & $34(50.7 \%)$ & $33(49.3 \%)$ & \\
\hline Tertiary & $45(39.5 \%)$ & $69(60.5 \%)$ & \\
\hline Residence & & $32(97.0 \%)$ & \\
\hline Rural & & & \\
\hline Urban & & & \\
\hline
\end{tabular}


The knowledge level of the study participants was determined using a dichromatic scale. A total of 9 knowledge statements were used ranging from whether one has had about preconception care and the components of preconception care services. Each yes answer statement earned the participant 1 point and a No answer earned 0 point.0-9points was used; where a participant who scored 0-6 points was considered to inadequate knowledge, while a participant who scored 6-9 points was considered to have adequate knowledge on preconception care. More than half of the study participants (68.7\%) had inadequate knowledge.

More than half of the participants in the study got the information and knowledge of preconception care in the hospital (67.8\%), followed by the internet (18.6\%).

Chi-square test was performed to find out the association between the knowledge level on preconception care and the socio-demographic variables. Table 5 shows the results where the knowledge level on preconception care was significantly associated with occupation $\left(X^{2}=20.345, \mathrm{df}=1, \mathrm{P}<0.05\right)$, level of education $\left(X^{2}=21.601, \mathrm{df}=4, \mathrm{P}<0.05\right)$ and residence of the participants $\left(\chi^{2}=16.56, \mathrm{df}=3, \mathrm{P}<0.05\right)$. The result shows that age has no association with the level of knowledge $\left(x^{2}=0.460, \mathrm{df}=1, \mathrm{P}>0.05\right)$.

Table 6 Chi-square Test of Knowledge level on Preconception Care against Number of Pregnancies of Participants

\begin{tabular}{|l|l|l|l|}
\hline Variable & Adequate & Inadequate & \\
\hline No. of pregnancy \\
\hline $1-2$ & $21(32.3 \%)$ & $44(67.7 \%)$ & \\
\hline $3-4$ & $23(33.8 \%)$ & $45(66.2 \%)$ & $X^{2}=1.705, \mathrm{df}=2, \mathrm{P}<0.05$ \\
\hline 5 and above & $3(17.6 \%)$ & $14(82.4 \%)$ & \\
\hline
\end{tabular}

The above result shows that the knowledge of preconception care was significantly associated with the number of pregnancies of the participants.

Table 7 Chi-square Test of Knowledge level of Preconception Care against Past Obstetrics Complications

\begin{tabular}{|l|l|l|l|}
\hline Variable & Adequate & Inadequate & \\
\hline \multicolumn{2}{|l|}{ Past obstetrics complications } \\
\hline None & $15(20.8 \%)$ & $57(79.2 \%)$ & \\
\hline Miscarriage & $13(48.1 \%)$ & $14(51.9 \%)$ & \\
\hline Still birth & $4(40.0 \%)$ & $6(60 \%)$ & $\mathrm{X} 2=11.7, \mathrm{df}=4, \mathrm{P}<0.05$ \\
\hline Prolonged labour & $3(75.0 \%)$ & $1(25.0 \%)$ & \\
\hline Preeclampsia & $2(50 \%)$ & $2(50 \%)$ & \\
\hline
\end{tabular}

The result shows that the level of knowledge of preconception care is significantly associated with past obstetrics complications of the participants. From the outcome, women with previous pregnancies and birth challenges tend to be more knowledgeable on preconception care in spite of the general low level of knowledge.

Generally, there was a poor practice of the components of preconception care as none of the components had up to $50 \%$ practice by the participants. However, the result shows that folic acid supplementation prior to pregnancies had the highest percentage of practice (38\%) followed by screening for HIV (31.3\%).Tetanus immunization prior to pregnancy was the least practiced (14.7\%). 
Table 8 Components of Preconception Care and its Practice amongst participants

\begin{tabular}{|l|l|l|}
\hline Variable & Yes & No \\
\hline Family Planning & $24(16.0 \%)$ & $126(84.0 \%)$ \\
\hline Tetanus toxoidimmunization & $22(14.7 \%)$ & $128(85.3 \%)$ \\
\hline Screening for HIV & $47(31.3 \%)$ & $103(68.7 \%)$ \\
\hline Screening for Hepatitis & $41(27.3 \%)$ & $106(70.7 \%)$ \\
\hline Screening for Diabetes & $36(24.0 \%)$ & $113(75.3 \%)$ \\
\hline Screening for Hypertension & $41(27.3 \%)$ & $108(72.0 \%)$ \\
\hline Screening for Syphilis & $40(26.7 \%)$ & $107(71.3 \%)$ \\
\hline Folic acid use before Pregnancy & $57(38.0 \%)$ & $90(60.0 \%)$ \\
\hline
\end{tabular}

Table 9 Chi-square test of Practice of Folic acid supplementation prior to pregnancy against Socio-demographic variables and Obstetrics history.

\begin{tabular}{|c|c|c|c|}
\hline Variables & Yes & No & \\
\hline \multicolumn{4}{|l|}{ Age of participants } \\
\hline $15-24$ & $9(52.9 \%)$ & $8(47.1 \%)$ & \\
\hline $25-34$ & $31(33.7 \%)$ & $58(63.3 \%)$ & $\mathrm{X} 2=4.165, \mathrm{df}=1, \mathrm{P}=0.980$ \\
\hline $35-44$ & $16(41.0 \%)$ & $23(59.0 \%)$ & \\
\hline$>44$ & $1(50.0 \%)$ & $1(50.0 \%)$ & \\
\hline \multicolumn{4}{|c|}{ Occupation of participants } \\
\hline Student & $4(28.6 \%)$ & $10(71.4 \%)$ & \\
\hline Employed & $26(50.0 \%)$ & $26(50.0 \%)$ & $\mathrm{X} 2=11.567, \mathrm{df}=1, \mathrm{P}=0.773$ \\
\hline Self employed & $22(37.0 \%)$ & $36(61.0 \%)$ & \\
\hline Unemployed & $5(22.7 \%)$ & $17(77.3 \%)$ & \\
\hline \multicolumn{4}{|l|}{ Level of education } \\
\hline No formal education & $0(0.0 \%)$ & $4(100.0 \%)$ & \\
\hline Primary & $3(30.0 \%)$ & $7(70.0 \%)$ & $\mathrm{X} 2=10.884, \mathrm{df}=1, \mathrm{P}=0.817$ \\
\hline Secondary & $22(32.4 \%)$ & $44(64.7 \%)$ & \\
\hline Tertiary & $31(46.3 \%)$ & $35(52.2 \%)$ & \\
\hline \multicolumn{4}{|l|}{ Residence } \\
\hline Rural & $7(12.5 \%)$ & $26(78.8 \%)$ & $\mathrm{X} 2=7.436, \mathrm{df}=1, \mathrm{P}=0.828$ \\
\hline Urban & $49(43.3 \%)$ & $62(54.4 \%)$ & \\
\hline \multicolumn{4}{|c|}{ Number of pregnancies } \\
\hline $1-2$ & $28(43.1 \%)$ & $34(52.3 \%)$ & \\
\hline $3-4$ & $23(33.8 \%)$ & $45(66.2 \%)$ & $\mathrm{X} 2=5.845, \mathrm{df}=1, \mathrm{P}=0.665$ \\
\hline 5 and above & $6(35.3 \%)$ & $11(64.7 \%)$ & \\
\hline
\end{tabular}




\begin{tabular}{|l|l|l|l|}
\hline \multicolumn{4}{|l|}{ Past obstetrics complications } \\
\hline None & $22(33.3 \%)$ & $48(66.7 \%)$ & \\
\hline Miscarriage & $14(51.9 \%)$ & $13(48.1 \%)$ & \\
\hline Stillbirth & $5(50.0 \%)$ & $5(50.0 \%)$ & $\mathrm{X} 2=8.175, \mathrm{df}=1, \mathrm{P}=0.771$ \\
\hline Prolonged labor & $0(0.0 \%)$ & $4(100.0 \%)$ & \\
\hline Preeclampsia & $2(50.0 \%)$ & $2(50.0 \%)$ & \\
\hline
\end{tabular}

Folic acid supplementation being the most practiced from the study, its association with socio-demographic variable and obstetrics history was tested using chi-square. The result shows that there's no association between the practice of folic acid supplementation prior to pregnancy and age, occupation, residence, level of education and obstetrics history of the participants.

Table 10 shows the frequency distribution of the participant's perceived importance of folic acid supplementation prior to and during pregnancy. During the study, participants were asked in the questionnaire to state their perceived understanding on the importance of folic acid us prior to and during pregnancy. Their response was grouped into the above variables. The result shows that only about one-fifth of the participants have good knowledge of the importance of folic acid use prior to and during pregnancy (17.3\%). About half of the participants have no knowledge of the use of folic acid (49.3\%) and the rest (32\%) had wrong knowledge on the importance of folic acid use.

Table 10Participants perceived importance of Folic acid supplementation prior to and during pregnancy

\begin{tabular}{|l|c|c|}
\hline Variable & Frequency & Percentage (\%) \\
\hline No knowledge & 74 & 49.3 \\
\hline To boost immune system & 17 & 11.3 \\
\hline $\begin{array}{l}\text { To prevent neural tube defect } \\
\text { and for brain development }\end{array}$ & 26 & 17.3 \\
\hline Strong baby & 18 & 12.0 \\
\hline $\begin{array}{l}\text { Protect mother and baby from } \\
\text { diseases }\end{array}$ & 12 & 8.0 \\
\hline To stimulate appetite & 1 & 0.7 \\
\hline
\end{tabular}

Table 11 Chi-Square Test of Perceived importance of Preconception Folic acid supplementation against Sociodemographic Variables and Number of Pregnancies.

\begin{tabular}{|l|l|l|l|l|l|l|}
\hline Variable & \multicolumn{1}{|c|}{$\begin{array}{c}\text { No } \\
\text { Knowledge }\end{array}$} & \multicolumn{1}{|c|}{$\begin{array}{c}\text { To boost } \\
\text { immune } \\
\text { system }\end{array}$} & $\begin{array}{c}\text { To prevent } \\
\text { neural tube } \\
\text { defect }\end{array}$ & $\begin{array}{c}\text { Strong baby } \\
\text { and mother }\end{array}$ & \multicolumn{1}{|c|}{$\begin{array}{c}\text { To protect } \\
\text { baby and } \\
\text { mother }\end{array}$} & \\
\hline Age of participants & $10(13.5 \%)$ & $2(11.8 \%)$ & $4(15.4 \%)$ & $1(5.6 \%)$ & $0(0.0 \%)$ & \\
\hline $15-24$ & $47(63.5 \%)$ & $11(64.7 \%)$ & $14(53.8 \%)$ & $11(61.1 \%)$ & $7(58.3 \%)$ & $\begin{array}{c}\mathrm{X} 2=0.376, \\
\mathrm{df}=28, \mathrm{P}>0.05\end{array}$ \\
\hline $25-34$ & $17(23.0 \%)$ & $3(17.6 \%)$ & $7(26.9 \%)$ & $6(33.3 \%)$ & $5(41.7 \%)$ & \\
\hline$>44$ & $0(0.0 \%)$ & $1(5.9 \%)$ & $1(3.8 \%)$ & $0(0.0 \%)$ & $0(0.0 \%)$ & \\
\hline
\end{tabular}




\begin{tabular}{|l|l|l|l|l|l|l|}
\hline \multicolumn{2}{|l|}{ Level of education } \\
\hline $\begin{array}{l}\text { No formal } \\
\text { education }\end{array}$ & $2(21 \%)$ & $0(0.0 \%)$ & $1(3.8 \%)$ & $1(5.6 \%)$ & $0(0.0 \%)$ & \\
\hline Primary & $6(8.1 \%)$ & $3(17.6 \%)$ & $1(3.8 \%)$ & $0(0.0 \%)$ & $0(0.0 \%)$ & $\begin{array}{l}\mathrm{X} 2=0.846, \\
\mathrm{df}=21, \mathrm{P}>0.05\end{array}$ \\
\hline Secondary & $43(58.1 \%)$ & $5(29.4 \%)$ & $10(38.5 \%)$ & $7(38.9 \%)$ & $2(16.7 \%)$ & \\
\hline Tertiary & $23(31.1 \%)$ & $9(52.9 \%)$ & $13(50.0 \%)$ & $10(55.6 \%)$ & $10(83.3 \%)$ & \\
\hline Residence & \multicolumn{7}{|l|}{} & & \\
\hline Rural & $22(29.7 \%)$ & $4(23.5 \%)$ & $1(3.8 \%)$ & $4(22.2 \%)$ & $1(8.3 \%)$ & $\begin{array}{l}\mathrm{X} 2=0.452, \\
\mathrm{df}=21, \mathrm{P}>0.05\end{array}$ \\
\hline Urban & $51(68.9 \%)$ & $12(70.6 \%)$ & $24(92.3 \%)$ & $14(77.8 \%)$ & $11(91.7 \%)$ & \\
\hline Number of pregnancies & $28(37.8 \%)$ & $8(47.1 \%)$ & $16(61.5 \%)$ & $7(38.9 \%)$ & $4(33.3 \%)$ & \\
\hline $1-2$ & $34(45.9 \%)$ & $7(41.2 \%)$ & $8(30.8 \%)$ & $11(61.1 \%)$ & $7(58.3 \%)$ & $\begin{array}{l}\mathrm{X} 2=0.491, \\
\mathrm{df}=14, \mathrm{P}>0.05\end{array}$ \\
\hline $3-4$ & & & & & \\
\hline $4-5$ & $12(16.2 \%)$ & $2(11.8 \%)$ & $2(7.7 \%)$ & $0(0.0 \%)$ & $1(8.3 \%)$ & \\
\hline
\end{tabular}

The result shows that the participant's perceived importance has no association with age, level of education, residence and number of pregnancies of the participants.

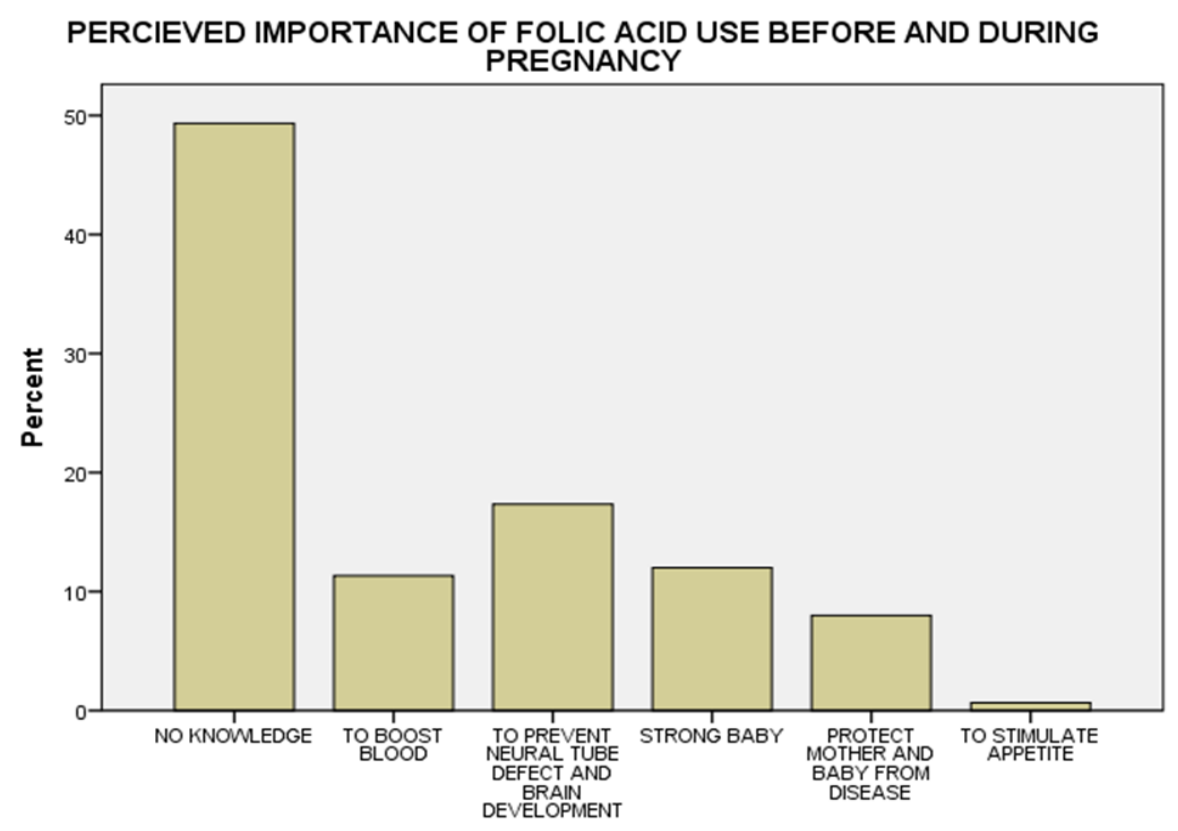

Figure 1 Perceived importance of folic acid use before and during pregnancy

The study showed that about half of the participant's reason for lack of uptake of preconception care was due to lack of knowledge (46.0\%). 10\% of the participants felt it was not relevant; in their words, "I've never had any problem with pregnancies so far, so no need going for preconception care." $6.7 \%$ lack of uptake was due to unplanned pregnancy, $6.0 \%$ had no reason for not going for preconception care despite having adequate knowledge of it, only $1.3 \%$ was due lack of partner's support. 


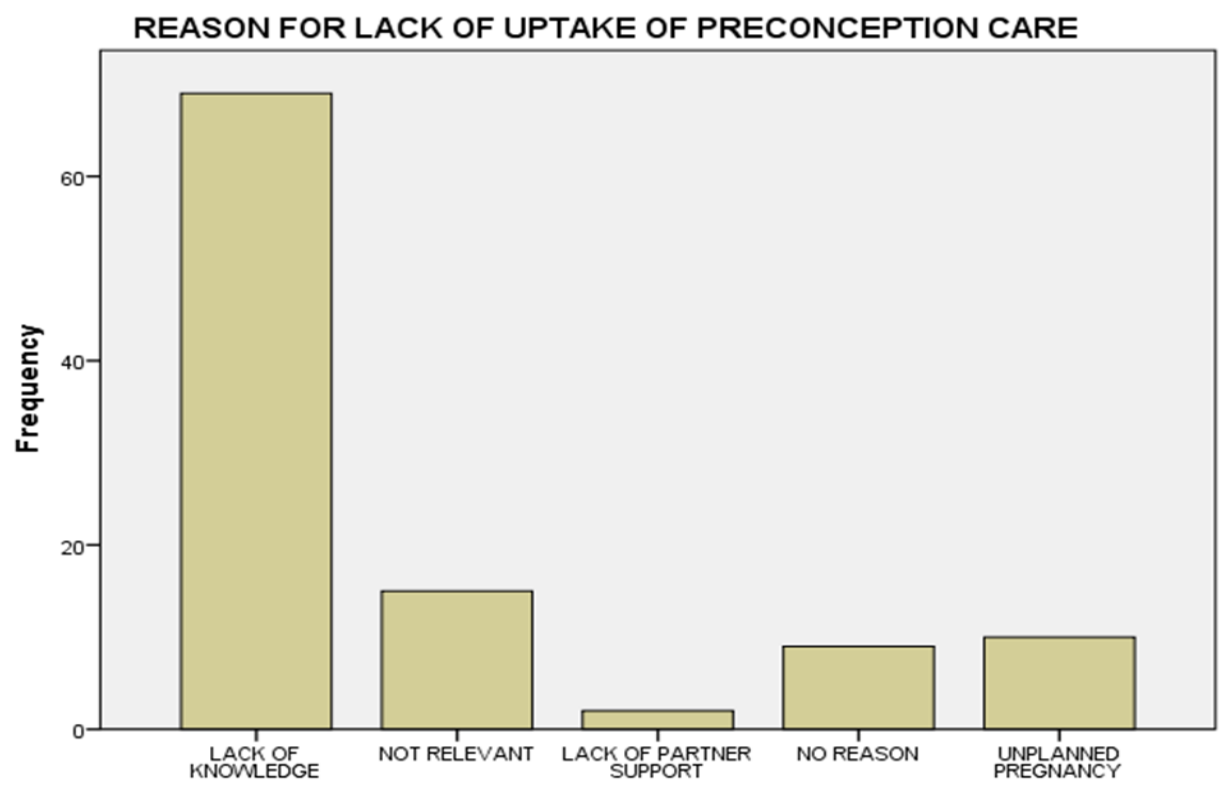

Figure 2 Reason for lack of uptake of perception care

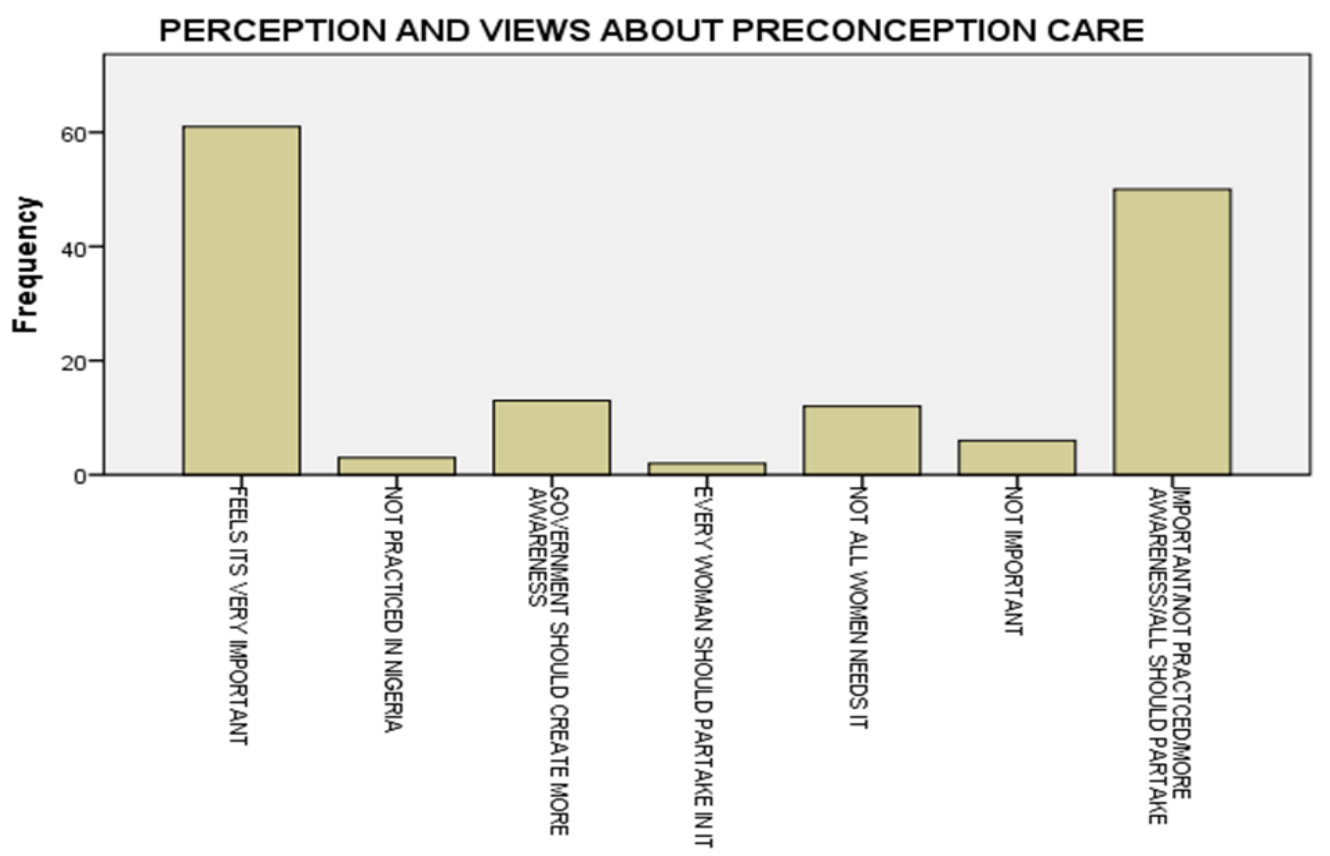

Figure 3 Perception and views about perception care

To sum up the data collection from each participant in the study, having explained what preconception care is all about to both those with adequate and inadequate knowledge, the participants were asked to express their perceived views, belief and ideas about preconception care. Their views were grouped into the above variables.40.7\% of participants believed it was important, $33.3 \%$ believed it was necessary they felt that it is not practiced in Nigeria and that the Nigerian government should create more awareness, more so, that every woman should partake in preconception care. Therefore, $87.7 \%$ of the participants had good views concerning preconception care. 


\section{Discussion}

The result shows that more than half of the participants were aged $25-34(61.3 \%)$,the rest were 35-44(26\%),15$24(11.3 \%)$ and the least age distribution were 45 and above(1.3\%).Nearly all the participants were Christians(98\%) and only $2 \%$ being muslim. $98.7 \%$ were married. On the residence of participants, more than three-quarter resided in the urban area (76.7\%).39.3\% of participants were self-employed, with $36.0 \%$ employed,9.3\% student and $15.4 \%$ unemployed. On educational level, about half of the participants had attained secondary level, $44.7 \%$ tertiary level, $7.3 \%$ with primary level and only $2.7 \%$ having no formal education. About half of the participants(45.3\% )has had about 3-4 pregnancies and $43.3 \%$ are having pregnancy at the time of study or are in their second pregnancy, only $11.3 \%$ has had about five or more pregnancies. On the past obstetrics complications, more than half of the participants(61.5\%) never had any complication in their previous pregnancies, $23.1 \%$ has had a miscarriage,8.5\% stillbirth,3.4\% prolonged labor and $3.4 \%$ preeclampsia.

In assessment of the knowledge of preconception care, only $31.3 \%$ of the study participants attending antenatal clinic at NAUTH ,Nnewi, anambra state, Nigeria were knowledgeable of Preconception care as they were able to answer about 6-9 out of the dichromatic scale containing about 9 questions. This shows a poor knowledge and awareness in Nigeria. More than half of the participants in the study got the information and knowledge of preconception care in the hospital (67.8\%), followed by the internet (18.6\%). this findings agree with a previous studies carried out in UDUTH Sokoto, Nigeria, in which only $20.61 \%$ of 131 women recruited by simple random sampling via antenatal care clinic were aware of preconception care. ${ }^{8}$ this is also in keeping with a community based study done in Adet, West gojjam, northeast Ethiopia $^{7}$. The study revealed that overall knowledge of Preconception care was 27.5\% (95\% CI:23.2,32.0). However, a study done at the University Teaching Hospital, Idi-Araba, Lagos, Nigeria amongst pregnant women is in disagreement with this study findings stating that there is a high level of awareness and knowledge of Preconception care (76\%). ${ }^{19}$ Also, a study done among women in Ife central Local Government Area of Osun, Nigeria in disagreement with the study findings showed that most $(63.5 \% ; n=238)$ of the respondents were aware of preconception care and the main source of awareness was the antenatal clinic. ${ }^{10}$ This disparity could be as a result of the fact that Lagos is a metropolitan city with high number of well learned individual from different works of life and maybe due to the high level of media involvement in health.

The study revealed that there was a significant relationship between the knowledge of preconception care and the women's educational status, residence and occupation. This shows that the knowledge of Preconception care increases significantly with the women's educational level, as women with secondary education are more knowledgeable than women with primary education and that of women with tertiary education more knowledgeable than women with secondary education. Same as residence, urban dwellers are more knowledgeable than rural dwellers, same as for occupation. However, the study findings showed that the knowledge of Preconception care is not associated the age of the participants. This findings is in keeping with a study of women receiving antenatal care at the University of Nigeria Teaching Hospital and Enugu State university teaching hospital(ESUT) between October 2005 and March 2006 with the objective of determining the awareness and practice of preconception care in south eastern Nigeria revealed that the respondent's awareness of preconception care and their ability to define the subject correctly increase significantly with their educational status. ${ }^{9}$ Also, a descriptive cross-sectional study conducted in Isfahan hospitals(Iran) in 2016 agreed with the finding, it showed that $47.7 \%$ of participants had received preconception care and there was a significant relationship between educational levels, income, wanted pregnancy, number of pregnancies, with preconception care $(\mathrm{P}<0.05) .{ }^{13}$ Also, in agreement with the finding, a study whose aim is to determine the effect of socio-demographic factors on the utilization of maternal health care services in Uganda found out that the main demographic determinants having an influence on the preconception care preparedness included residence, education, marital status, parity and deliveries of the respondents. ${ }^{15}$ Therefore, the study concludes that efficiency preconception preparedness initiatives made by both the hospital and the mothers is largely dependent on these demographic determinants. ${ }^{15}$ However, in a bit of disagreement with the research findings, a community based study done in Adet, West gojjam, northeast Ethiopia ${ }^{7}$ revealed that women's age is one of the three vital variables(age, history of family planning and educational status) associated with the knowledge of Preconception care. The age not being a factor in the study could be as a result of limited sample size.

Still on the predictors or facilitators of the knowledge of Preconception care, the study shows that the knowledge of preconception care was significantly associated with the number of pregnancies of the participants and their past obstetrics challenges. From the outcome, women with previous pregnancies and birth challenges tend to be more knowledgeable on preconception care in spite of the general low level of knowledge. Based on the findings, miscarriage was the commonest obstetrics complication (23.1\%) with a 48.1\% adequate knowledge as against 20.8\% knowledge of those with no past obstetrics complications. This is in keeping with previous studies, Ishamael K. Acheampong Y et al, 
which reports that previous deliveries of the respondents is one of the main factors affecting women's preconception preparedness. This report, hereby solidify the findings.

The study revealed a poor practice of preconception care (28\%). From the findings, the few participants who practiced Preconception never had practiced the full components outlined in the study questionnaire as none of the components had up to $50 \%$ practice by the participants. However, the result shows that folic acid supplementation prior to pregnancies had the highest percentage of practice (38\%) followed by screening for HIV (31.3\%).Tetanus immunization prior to pregnancy was the least practiced (14.7\%).This is in keeping with a study done among reproductive age group women in Debre Birhan town, North Shewa, Ethiopia which revealed a poor utilization of $13.4 \% .{ }^{20} \mathrm{Also}$, a study carried out at the Lagos University Teaching Hospital, Idi-Araba, lagos,Nigeria showed that majority of the respondents (26.7\%) received folic acid supplementation as preconception care. ${ }^{18}$ However, the study revealed that participants felt it was necessary to practice Preconception care despite having no prior knowledge on what Preconception care is all about as they deemed it necessary to screen themselves against certain diseases before getting pregnant. This is evident by percentage of folic acid supplementation (38\%) as a single most common component of practice to that of knowledge of Preconception care (31.3\%). This finding has not been seen in previous studies.

Folic acid supplementation being the most practiced component of preconception care amongst the study participant was further analyzed, findings showed that that there's no association between the practice of folic acid supplementation prior to pregnancy and age, occupation, residence, level of education and obstetrics history of the participants. Participants were asked in the questionnaire to state their perceived understanding on the importance of Folic acid use prior to and during pregnancy. The result shows that only about one-fifth of the participants have good knowledge of the importance of folic acid use prior to and during pregnancy (17.3\%). About half of the participants have no knowledge of the use of folic acid (49.3\%) and the rest (32\%) had wrong knowledge on the importance of folic acid use. This is in keeping with a previous study on knowledge, attitude and practice of folic acid among pregnant women in Benghazi, Libya which shows that only $37 \%$ of the participants could correctly identify the effect and importance of folic acid when used periconceptionally. ${ }^{21}$ The study went further to access the relationship of the participant's perceived importance and their socio-demographic variables and their obstetrics history, the result showed that the participant's perceived importance has no association with age, level of education, residence and number of pregnancies of the participants.

Furthermore, the study probed into participant's reason for lack of uptake of preconception care through an open statement section of the semi structured interviewer and self-administered questionnaire. The study showed that about half of the participant's reason for lack of uptake of preconception care was due to lack of knowledge (46.0\%). $10 \%$ of the participants felt it was not relevant; in their words, "I've never had any problem with pregnancies so far, so no need going for preconception care." $6.7 \%$ lack of uptake was due to unplanned pregnancy, $6.0 \%$ had no reason for not going for preconception care despite having adequate knowledge of it, only $1.3 \%$ was due lack of partner's support. Lastly, an open statement section of the questionnaire with the aim of obtaining participants views, ideas and beliefs of preconception care having explained what preconception care is all about to both those with adequate and inadequate knowledge. Findings showed that $40.7 \%$ of participants believed it was important, $33.3 \%$ believed it was necessary, they felt that it is not practiced in Nigeria and that the Nigerian government should create more awareness, more so, that every woman should partake in preconception care. This shows that Preconception care will be highly accepted and practiced by Nigerian women if more awareness is created.

\section{Conclusion}

The following conclusions were made from the study. There is a low level of knowledge of preconception care among the study participants with a larger proportion who have never heard about it and not able to correctly choose the components of preconception care outlined in the questionnaire and the main source of information was obtained from the health workers in the hospital.

The factors that were found to be perceived facilitators on the knowledge and practice of preconception care include, occupation, educational status of the women, residence, number of pregnancies and past obstetrics history.

Preconception folic acid supplementation was the most practiced component. There is a poor level of knowledge on the importance of folic acid use prior to and during pregnancy (17.3\%).

The participants have positive and encouraging views on the uptake of preconception care in Nigeria as majority felt it should be encouraged and practiced by every women of child bearing age seeking pregnancy. 


\section{Study Limitations}

- The data collection was delayed due to the bureaucracy involved in getting ethical approval.

- The antenatal clinic had about 25 women attending antenatal clinic during working days thereby prolonging the duration of data collection to 3 weeks which was indeed tedious.

- The random sampling technique could only allow about 10 data collection per day thereby necessitating the duration of study of 3 weeks.

- Majority of the women come for weekly and 2 weekly antenatal visits as same women were seen during the $2^{\text {nd }}$ and $3^{\text {rd }}$ week of data collection therefore, the attrition size could not be achieved.

\section{Recommendations}

- Health education of women age on preconception care services, its components and importance in the health facilities and institutions of higher learning so that they can have the knowledge on preconception care hence increasing its utilization. This is because the knowledge and uptake is influenced by the level of education.

- The ministry of Health at the national and state level to increase public awareness on preconception care through mass media, mobile clinics, churches, women groups so as to increase the uptake of preconception care services.

- Development of preconception care clinic at every primary health care in the state to create easier access to preconception care.

- Every health care worker should be fully educated on preconception care and its components as this will strengthen the awareness of preconception care.

- More research studies should be done in determining women's views and opinion about preconception care in rural areas in order to clear their misconceptions about preconception care as residence also influences the knowledge and uptake of preconception care.

- Educating the women on the importance of folic acid supplementation in health facilities as this will strengthen their spirit in practice of preconception care.

\section{Compliance with ethical standards}

\section{Acknowledgments}

This research received no specific grant from any funding agency in the public, commercial, or not-for-profit sectors.

\section{Disclosure of conflict of interest}

Authors declare that there is no competing interest.

\section{Statement of informed consent}

According to the research design, voluntary informed consent was gotten from the participants after adequate data concerning the aim of the study and guarantee of confidentiality were given. Our recruitment script illustrated the objectives of the study, its significance, implications, and probable risks. Moreover, it specified anonymity and voluntarity of participation, and thus non-participation did not impose any consequence whatsoever, and they were free to exclude from the research whenever they are no longer comfortable with the study.

\section{References}

[1] World Health Organization. Preconception Care: Maximizing the gains for maternal and child health[internet].2013.

[2] Yitayal A, Amlaku M, Amare S. Women's knowledge and associated factors in preconception care in Adet, West gojjam, northwest Ethiopia [internet]2017[assessed on Aug 9 2019].

[3] Chepngetich J, Margaret K, Joan N. Assessment of the knowledge on preconception care among women of reproductive age in Ruiru sub-county, Kiambu county, Kenya[internet].2018. 
[4] Nwafor. Global worry over Nigeria's low rating in maternal health. 2018.

[5] Hibbert E.J, Chalasani S, Kozan P,Myszka R,Park KEJ, Black KI. Preconception care and contraceptive use among Australian women with diabetes mellitus. Aust J Gen Pract.2018.

[6] Elsinga J, Jong-potjer LC, Van der Pal-de Bruin KM, Le Cessie S, Assendelft WJ, Buitendijk SE. The effect of preconception counseling on lifestyle and other behavior before and during pregnancy: Women's Health Issues. 2008 Nov-Dec; 18.

[7] Sijpkens MK,Sabine F,Eric A.The effect of preconception care outreach strategy:the Healthy Pregnancy 4 All study.BMC Health Services Research. 2019

[8] ACOG.Good health before pregnancy: pregnancy care. 2018.

[9] Ezegwui H, Dim C, Dim N, Ikeme A.C. Preconception care in South Eastern Nigeria. Journal of Obstetrics and Gynecology. 2019.

[10] DieulaDelissaint. Exploring the factors associated with preconception health behaviors among women of childbearing age. Aug 2008.

[11] Fransen MP, Hopman ME, Murugesu L, et al. Preconception counseling for low health literate women:an exploration of determinants in the Netherlands. Reproductive Health.2018.

[12] Joyce B, Abadnego O. Influence of demographic determinants on preconception care preparedness among women seeking postnatal and family planning services.

[13] Xinliang Z, Xiaoqing J, Yaping T. Factors influencing the quality of preconception instrumental to assess healthcare needs[internet].BMC Pregnancy and Childbirth. 2014

[14] Zhao X, Zhu J, li G, He X, et al. Factors influencing the quality of preconception healthcare in China: applying a preconception instrument to access healthcare needs[internet].BMC Pregnancy Childbirth.2014 Nov 3.

[15] Ishmael K,Acheampong Y,Mirriam N. The effect of socio-demographic factors on the utilization of maternal health care services in Uganda. African population studies. April 2014; 28(1).

[16] Elsinga J,Karin M,lieke C.The effect of preconception counseling on lifestyle and other behavior before and during pregnancy. Women's health. November 2008; 18.

[17] Tasneem K,Shelley M,Estelle D.Physical activity and the risk for gestational diabetes mellitus amongst pregnant women living in Soweto: a study protocol.BMC Women's Health. 2016; 16(66).

[18] Adeoye TO, Kolawole AO, Onwuhuafua P, Adeoye GO. Awareness and perception of preconception care among health workers in Ahmadu Bello University Teaching Hospital,Zaria. Tropical journal of Obstetrics and Gynaecology. 33.

[19] Opeyemi RA, Gbemi EO, Osemen EO. Assessing the level of awareness, knowledge and practice amongst pregnant women in a tertiary facility. Department of obstetrics and gynecology, Lagos state University Teaching Hospital, Idi-araba, Lagos, Nigeria. 2019.

[20] Tesfanesh LD, Samuel AA, Mulualem SZ. Utilization of preconception care and associated factors among reproductive age group women in Delore Birhan town,North shewa,Ethiopia. 2019.

[21] Abdulmalek,Lubna. Knowledge,attitude and practice regarding folic acid among pregnant women in Benghazi, Libya. [assessed on Oct 12 2019].

[22] Onwutalobi, Anthony-Claret. "Nnewi Industrialization overview - The Official Nnewi City Portal". www.nnewi.info. Retrieved 2020-09-19.

[23] National Population Commission Census 2006

[24] Nnamdi Azikiwe University Teaching Hospital Nnewi. 